\title{
Roots from mulberries (Morus alba) natural and hybrids varieties: phenolic contend and nutraceutical potential as antioxidant
}

\author{
Denise Sande $^{1^{*}}$, Maykelis Díaz Solares ${ }^{2}$, Yanio Enrique Milián Rodríguez ${ }^{2}$, Inelvis Castro Cabrera ${ }^{2}$, Leydi Fonte \\ Carballo $^{2}$, Nancy Altunaga Pérezb ${ }^{2}$, Yudit Lugo Moralesb ${ }^{2}$, Gecernir Colenc ${ }^{3}$, Jacqueline Aparecida Takahashia ${ }^{1}$ \\ ${ }^{1}$ Department of Chemistry, Exact Sciences Institute, Universidade Federal de Minas Gerais, Brazil. \\ ${ }^{2}$ Estacíon Experimental de Pastos y Forrajes "Indio Hatuey", Universidad de Matanzas, Cuba. \\ ${ }^{3}$ Department of Food, Faculty of Pharmacy, Universidade Federal de Minas Gerais, Brazil.
}

\section{ARTICLE INFO}

\section{Article history:}

Received on: 05/08/2016

Revised on: 14/09/2016

Accepted on: 30/09/2016

Available online: 29/11/2016

Key words:

Morus alba varieties;

mulberry; root; antioxidant;

radical scavenging.

\begin{abstract}
Fruits of Morus alba have been described as source of phytochemicals with antioxidant activity, which is of interest for human consume, and food industry. However, differences in antioxidant capacity among varieties of this species, as well as the potential of other parts of this plant has been little explored. In this work, extracts of roots from twelve (natural or hybrid) varieties of $M$. alba were evaluated. There were observed differences between varieties, as the range of total phenol content among hexane, ethanol and aqueous extracts $(0.55-1.59$; $2.72-6.61 ; 5.09-9.85$ gallic acid $/ 100 \mathrm{~g}$ of extract, respectively). Antioxidant action of M. alba roots extracts was proved in different assays as radical scavenger and iron reduction capacity. Ethanol was found to be the best solvent to extract antioxidant compounds. Among all extracts assayed, the best association between high phenol and flavonoid content associated to free radicals scavenger and iron reducing power activities were shown by ethanol root extract from hybrid variety IZ 64. This work demonstrated that $M$. alba roots possess great potential as source of phytochemicals with antioxidant activity and pointed variety IZ 64 as the best cultivar to be used due to its functional properties or as source of natural antioxidants.
\end{abstract}

\section{INTRODUCTION}

Morus alba is a plant species that belongs to Moraceae family and has high economic interest worldwide (Donno et al., 2015). Its fruits are source of alkaloids, flavonoids, anthocyanins and phenolic acids, being used as human food while its foliage contains unique nutrients for silkworm development (Butt et al., 2008; Chan et al., 2016). This plant species is native to Asia, but due to its wide adaptation in the tropics (Europe, north and south America, Africa and India), it has been considered cosmopolitan nowadays (Noda et al., 2004; Khan et al., 2013). Sericulture was the main process that drove the improvement of $M$. alba species leading to the development of varieties that represent valuable plant genetic resources. In Brazil, for example, there are three

\section{* Corresponding Author}

Denise Sande, Department of Chemistry, Exact Sciences Institute, Universidade Federal de Minas Gerais, Brazil.

Email: sandebiom@gmail.com collections of $M$. alba which bears 90 varieties (Medina et al., 2009). In Cuba, the Estacion Experimental de Pastos y Forrajes Indio Hatuey (EEPF-IH) is one of the centers for genetic improvement of $M$. alba for sericulture holding a gene bank with varieties obtained from countries like Costa Rica, South Korea, China and Spain (Martín et al., 2014). Among the varieties available at EEPF-IH, it is worth mentioning Cuban, Indonesia, Murcia, Tigreada, University, YU-12, YU-62 (natural ones) and IZ 13/6, IZ15/7, IZ 40, IZ 56/4 and IZ 64 (hybrid ones) which have been developed by different agronomic studies. Besides the nutritional value of Morus fruits, other parts of this plant have been related to possess biological activities such its stems, with antioxidant (Nam et al., 2012), antiulcer (Ahmad et al., 2013) and anti-inflammatory activities (Rivière et al., 2014). For $M$. alba leaves, vasodilator (Kurniati et al., 2014) and hyperglycemia reducing effects (Kim et al., 2011) have been reported while antityrosinase activity (Chang et al., 2011) was reported for M. alba twigs. 
The fruits were also pointed to carry on macrophage activation (Kim et al., 2013) and to bear antioxidant activity (Donno et al., 2015). Lyophilized extract of Morus fruits displayed significant wound healing activity (Akkol et al., 2015). Root barks also have shown biological activity as hypocholesterolemic, antioxidant (El-Beshbishy et al., 2006), anti-inflammatory and anti-cancer agents (Eo et al., 2014). It is important to note also that there are already proving the absence of toxicity studies on oral administration of extracts of Morus alba (Oliveira et al., 2016).

Phenolic compounds are secondary metabolites that protect plants against damage from pathogens and environmental stress (Paredes-López et al., 2010). The consumption of these substances has been correlated with minimizing damaging effects of uncontrolled free radicals production, due to their antioxidant activity (Yangthong et al., 2009). Mechanisms of antioxidant action are very complex, including electrons donation, which act accelerating lipids oxidation (El-Beshbishy et al., 2006; Huang et $a l ., 2005)$. Other mechanisms include hydrogen donation to reduce reactive oxygen species (Villaño et al., 2007) related to alterations in DNA and cancer. Phenolic compounds concentration and, consequently, antioxidant activity of any plant is greatly affected by environmental conditions, storage, geographic region, variety and the part of plant used in the biological evaluation (ParedesLópez et al., 2010). In the literature there are only a few reports regarding biological activities of $M$. alba roots extracts (ElBeshbishy et al., 2006; Eo et al., 2014), since the studies on $M$. alba roots usually concentrated in their barks and not in the whole roots (Wei et al., 2016). The use of roots in food as a source of metabolites with biological activity is underexploited in the literature although of great interest. Zingiber officinale rhizome, for instance, is greatly used to compose the taste of soft drinks and beverages and has been proved to possess antioxidant activity higher than butylhydroxyanisole, a synthetic compound used to prevent food oxidation (Singh et al., 2008).

Due to toxicity associated to synthetic antioxidants used as preservatives in some foods, legal restrictions have been imposed to their use. On the other hand, the growing knowledge of healthy effects of nutraceuticals in the daily diet has been increasing the search for novel natural antioxidants (Butt et al., 2008; Egea et al., 2010). In this context, the aim of the present work was to evaluate and compare phenolic and flavonoid contents in extracts prepared from roots of different natural and hybrid $M$. alba varieties, and to determine their antioxidant activities by different mechanisms aiming at determining the antioxidant potential of $M$. alba roots.

\section{MATERIALS AND METHODS}

\section{Chemicals}

All chemicals used in this work were of analytical grade. Solvents (ethanol, methanol and hexane), acids and salts were obtained from Vetec Química fina LTDA (Rio de Janeiro, Brazil), except for ascorbic acid, quercetin, 2,2'-azinobis-3etilbenzotiazolin-6-sulfonic (ABTS), 1, 1-Diphenyl-2- picrylhydrazyl (DPPH), hidroquinone, and gallic acid, that were purchased from Sigma-Aldrich (São Paulo, Brazil). FolinCiocalteu reagent was purchased from Merck (Darmstadt, Germany).

\section{Plant material and extracts preparation}

All plants used at this work were obtained from Estacion Experimental de Pastos y Forrajes "Indio Hatuey". Twelve varieties of $M$. alba were used: Cubana, Indonesia, IZ 13/6, IZ 15/7, IZ 40, IZ 56/4, IZ 64, Murcia, Tigreada, Universidad, YU 12 and YU 62. The dried roots of each variety ( $1 \mathrm{~kg}$ ) were milled and successfully extracted from hexane, ethanol and distilled water by percolation. After exhaustive extraction, the solvent was removed under vacuum. There were obtained 36 extracts that were labeled and stored at $4{ }^{\circ} \mathrm{C}$.

\section{Total antioxidant activity (phosphomolybdate method)}

Phosphomolybdate assay was used to evaluate extracts capacity to reduce $\mathrm{Mo}^{+6}$ (yellow) to $\mathrm{Mo}^{+5}$ (green) in acid $\mathrm{pH}$ (Prieto et al., 1999). Extracts were dissolved in hexane, ethanol or water $(0.1 \mathrm{~mL})$ and $3 \mathrm{~mL}$ o reagent solution $(0.6 \mathrm{M}$ sulfuric acid, $28 \mathrm{mM}$ sodium phosphate, $4 \mathrm{mM}$ ammonium molybdate) were gently mixed and incubated for $90 \mathrm{~min}$ at $95{ }^{\circ} \mathrm{C}$. Samples were cooled to room temperature and absorbance was read at $695 \mathrm{~nm}$ against a blank containing only the solvent and reagent solution. Ascorbic acid was used as reference standard and total antioxidant activities of the extracts from the different varieties assayed were expressed as ascorbic acid equivalents (mmol ascorbic acid/g dry weight of the root extracts).

\section{Iron reducing power}

Iron reducing antioxidant capacity was evaluated by mixing $0.25 \mathrm{~mL}$ of extracts at concentrations varying from 12.5 to $100 \mu \mathrm{g} / \mathrm{mL}$ to phosphate buffer (0.2 M, pH 6.6) and $0.625 \mathrm{~mL}$ of potassium ferrocyanide $1 \%(\mathrm{w} / \mathrm{v})$. After homogenization, samples were incubated for $20 \mathrm{~min}$ at $50{ }^{\circ} \mathrm{C}$. Then $0.625 \mathrm{~mL}$ of trichloroacetic acid $10 \%(\mathrm{w} / \mathrm{v})$ was added and the contents were centrifuged $(3000 \mathrm{rpm}, 10 \mathrm{~min})$. Supernatant $(0.18 \mathrm{~mL})$ was added to $1.8 \mathrm{~mL}$ water and $0.36 \mathrm{~mL}$ ferric chloride $(0.1 \%$, w/v). Absorbance reading was taken at $700 \mathrm{~nm}$ and results were expressed as mean \pm standard deviation. Ascorbic acid was used as reference standard (Oyaizu, 1986).

\section{Radicals' scavenger antioxidant activities (ABTS and DPPH)}

Evaluation of radicals' scavenger antioxidant activities followed two methodologies. Scavenger ABTS method (Johnstone et al., 2006; Olajuyigbe and Afolayan, 2011) consisted into preparation of an ABTS solution ( $7 \mathrm{mM} \mathrm{ABTS}$ and potassium persulfate $2.4 \mathrm{mM}$ incubated for $12 \mathrm{~h}$ in dark). This solution was diluted with methanol until absorbance at $734 \mathrm{~nm}$ reached $0.708 \pm$ 0.001 . Then $1 \mathrm{~mL}$ of this solution was mixed with $1 \mathrm{~mL}$ of extracts solution in different concentrations $(2.5-125 \mu \mathrm{g} / \mathrm{mL})$ and the reaction took place for $7 \mathrm{~min}$ in dark. Absorbance readings at 734 nm were taken. Scavenger DPPH method (Brand-Williams et al., 
1995; Re et al., 1999) used consisted in gently mixing the extracts solutions in different concentrations $(100-1000 \mu \mathrm{g} / \mathrm{mL})$ with DPPH $0.3 \%$ in methanol. The reaction was allowed to take place for $30 \mathrm{~min}$ in dark. Then, absorbance at $517 \mathrm{~nm}$ was measured. In both assays, ascorbic acid was used as positive control, a blank was made with metanol/ethanol instead of the extracts and antioxidant activity was expressed as inhibition percentage, calculated using the formula: $\%$ inhibition = (blank absorbance sample absorbance) / blank absorbance x 100. Sample concentration required for capturing $50 \%$ of DPPH or ABTS radicals $\left(\mathrm{IC}_{50}\right)$ was obtained from an inhibition (\%) vs. concentration curve.

\section{Total phenolic compounds}

Concentration of total phenolic compounds on the extracts from roots of $M$. alba varieties was evaluated by adding the extracts $(0.5 \mathrm{~mL}, 1000 \mu \mathrm{g} / \mathrm{mL})$ to $2.58 \mathrm{~mL}$ of Folin-Ciocalteu reagent (Gao et al., 2000). After $3 \mathrm{~min}$, saturated sodium carbonate solution $(0.3 \mathrm{~mL})$ was added and the materials were incubated for $20 \mathrm{~min}$ at room temperature. Gallic acid was used as reference standard. Absorbance reading at $760 \mathrm{~nm}$ was taken and the results were expressed as gallic acid equivalents ( $\mathrm{g}$ gallic acid /100 g dry weight of the root extracts).

\section{Total flavonoids content}

Flavonoids content was evaluated by aluminum chloride method (Yang et al., 2007). Extracts $(0.5 \mathrm{~mL})$, water $(2.5 \mathrm{~mL})$ and sodium nitrite $5 \%(\mathrm{w} / \mathrm{v})(150 \mu \mathrm{L})$ were combined, and strongly agitated by vortex $(10 \mathrm{~s})$. After $5 \mathrm{~min}, 300 \mu \mathrm{L}$ of aluminum chloride $10 \%(\mathrm{w} / \mathrm{v}), 1 \mathrm{~mL}$ of $\mathrm{NaOH}(1 \mathrm{mM})$ and $550 \mu \mathrm{L}$ of water were added. This solution was homogenized and incubated at room temperature for $15 \mathrm{~min}$. Samples absorbance at $510 \mathrm{~nm}$ were taken and results were expressed in quercetin equivalents $(\mu \mathrm{g}$ quercetin/g dry weight of the root extracts).

\section{Statistical analysis}

The results were analyzed by ANOVA (one-way), Tukey's and Dunnett's multiple comparison tests. Microsoft Excel 2010 (Roselle, IL, USA) was used in data evaluation. Correlations between phenolic compound contents and antioxidant activities were evaluated by Pearson correlation coefficient (r) with $\mathrm{P} \leq$ 0.05 .

\section{RESULTS AND DISCUSSION}

Hexane, ethanol and aqueous extracts of roots from natural and hybrid varieties of $M$. alba were prepared resulting in a total of thirty six extracts. This approach enabled the comparison of extracts activity according to the polarity and to the cultivar variety. In fact, antioxidant activity varied significantly. Ethanol extracts were, in general, far more active than the respective aqueous extracts, while hexane ones were only weakly active. In fact, when extracts were screened using phosphomolybdate assay, the most active ones were those prepared from ethanol. Hybrid $M$. alba varieties IZ 15/7 and IZ 13/6 showed the better activities (891 and $815 \mathrm{mmol}$ ascorbic acid/g extract, respectively) (Figure 1) followed by the natural cultivars Tigreada, Murcia e Universidad. Aqueous extracts showed intermediary activity but none of the aqueous extracts was more active than the ethanol ones. Although they were not as active as the ethanol extracts, relevance of their activities is high since they indicate the possibility of their use in the form of teas, which can be a straightforward way to benefit from their antioxidant activity. None of the hexane extracts was significantly active in this assay.

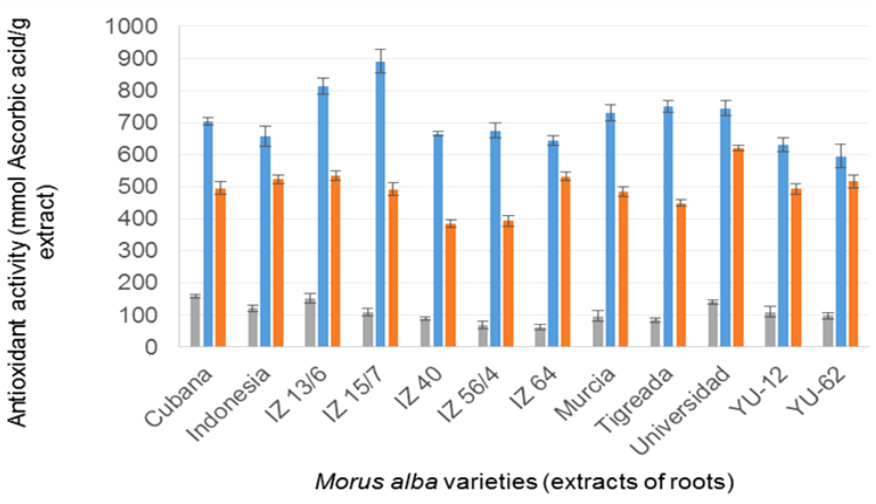

Fig. 1: Total antioxidant activity of extracts obtained by different solvents from roots of Morus alba varieties

On ferric ion reducing capacity, ethanol extracts were again the most active ones. Reducing power assay relies on the reduction of unstable $\mathrm{Fe}^{+3}$ to stable and $\mathrm{Fe}^{+2}$ (Umamaheswari and Chatterjee, 2008). The latter is more stable and unable to start or propagate lipid oxidation. Varieties IZ 64 (47.4\%), YU-62 (46.2\%) and IZ 13/6 (43.2\%) showed highest antioxidant activities, while natural cultivar Murcia and hybrid cultivar IZ 56/4 were much less active (28.8 and 28.4 respectively) (Table 1). Interestingly, aqueous extracts of varieties Universidad and Murcia were more active than the corresponding ethanol extracts. These data show the importance of assaying different cultivars and different extracts, since a straight correlation was not observed regarding this biossay. Although the standard used in this assay (ascorbic acid) was twice more active than the extracts, it is important to point that extracts are a mixture of many metabolites present in small yields. Therefore, extracts activities found in this work are very relevant and higher than ferric ion reducing capacity activity reported for extracts of $M$. indica L. leaves (10.37\%) (ArabshahiDelouee and Urooj, 2007). Among the aqueous extracts, besides Universidad and Murcia, the varieties IZ 64, YU-12 and Cubana were the most active for reducing ferric iron power activity (Table 1). Extracts able to avoid the action of iron ions present in food can prevent lipid oxidation process, being potential natural preservatives. The high activity of varieties IZ 64, YU-62, IZ 13/6 (as ethanol extracts), Murcia (33.2\%), IZ 64 (32.6\%), YU-12 $(32.2 \%)$ and Cubana (30.2\%) (as aqueous extracts) make these extracts good targets for development of natural food preservatives. 
Table 1: Ferric reducing power antioxidant activity of M. alba varieties roots extracts.

\begin{tabular}{|c|c|c|c|c|c|c|}
\hline \multirow{2}{*}{ M. alba varieties } & \multicolumn{6}{|c|}{ Absorbance at $700 \mathrm{~nm}$} \\
\hline & hexane & $\%^{a}$ & ethanol & $\%^{b}$ & aqueous & $\%^{\mathrm{c}}$ \\
\hline Ascorbic acid & 1.65 & 100 & 1.95 & 100 & 2.59 & 100 \\
\hline Cubana & 0.15 & 9.3 & 0.81 & 41.4 & 0.78 & 30.2 \\
\hline Indonesia & 0.18 & 11.1 & 0.66 & 33.6 & 0.68 & 26.1 \\
\hline IZ 13/6 & 0.09 & 5.6 & 0.84 & 43.2 & 0.65 & 25.0 \\
\hline IZ $15 / 7$ & 0.06 & 3.7 & 0.69 & 35.3 & 0.68 & 26.4 \\
\hline IZ 40 & 0.04 & 2.4 & 0.67 & 34.3 & 0.64 & 24.7 \\
\hline IZ 56/4 & 0.04 & 2.2 & 0.56 & 28.4 & 0.60 & 23.2 \\
\hline IZ 64 & 0.10 & 6.3 & 0.92 & 47.4 & 0.85 & 32.6 \\
\hline Murcia & 0.05 & 2.7 & 0.56 & 28.8 & 0.86 & 33.2 \\
\hline Tigreada & 0.06 & 3.8 & 0.80 & 40.9 & 0.75 & 28.8 \\
\hline Universidad & 0.11 & 6.6 & 0.74 & 37.8 & 1.01 & 38.8 \\
\hline YU-12 & 0.12 & 7.0 & 0.67 & 34.4 & 0.84 & 32.2 \\
\hline YU-62 & 0.11 & 6.6 & 0.90 & 46.2 & 0.71 & 27.3 \\
\hline Mean & & 5.6 & & 37.6 & & 29.0 \\
\hline
\end{tabular}

${ }_{a, b, c}$ Percentages calculated considering the absorbance of ascorbic acid in each solvent, as $100 \%$.

Table 2: Radicals scavenger activities (ABTS/DPPH) and phenol contents of $M$. alba varieties

\begin{tabular}{|c|c|c|c|c|c|c|c|c|c|}
\hline \multirow{2}{*}{$\begin{array}{c}\text { M. alba } \\
\text { varieties }\end{array}$} & \multicolumn{3}{|c|}{ DPPH $^{\text {a }}$} & \multicolumn{3}{|c|}{$\mathbf{A B T S}^{\mathbf{b}}$} & \multicolumn{3}{|c|}{ Phenol $^{\mathrm{c}}$} \\
\hline & hexane & ethanol & aqueous & hexane & ethanol & aqueous & hexane & ethanol & aqueous \\
\hline Cubana & 1824.2 & 429.0 & 812.1 & 326.3 & 23.8 & 87.4 & 0.64 & 7.49 & 3.70 \\
\hline Indonesia & 1916.6 & 733.6 & 1014.0 & 91.2 & 34.8 & 75.1 & 1.00 & 5.67 & 4.13 \\
\hline IZ 13/6 & 1215.0 & 642.2 & 866.8 & 509.0 & 29.1 & 112.3 & 0.55 & 7.29 & 6.61 \\
\hline IZ $15 / 7$ & 563.4 & 599.4 & 654.3 & 158.6 & 36.5 & 87.4 & 1.59 & 6.90 & 3.50 \\
\hline IZ 40 & 539.6 & 568.8 & 791.5 & 89.9 & 28.6 & 69.0 & 1.25 & 7.09 & 2.89 \\
\hline IZ 56/4 & 1191.3 & 792.6 & 839.0 & 178.2 & 34.3 & 83.0 & 1.09 & 6.15 & 2.73 \\
\hline IZ 64 & 808.8 & 378.1 & 717.1 & 204.6 & 13.2 & 53.8 & 1.29 & 9.85 & 4.21 \\
\hline Murcia & 593.2 & 667.7 & 912.9 & 169.2 & 37.8 & 94.4 & 1.31 & 5.09 & 3.53 \\
\hline Tigreada & 1344.9 & 591.8 & 615.1 & 187.7 & 29.5 & 85.0 & 1.53 & 7.48 & 3.44 \\
\hline Universidad & 2013.5 & 826.5 & 842.8 & 315.2 & 33.2 & 85.9 & 0.91 & 6.19 & 5.88 \\
\hline YU-12 & 1210.0 & 934.6 & 1069.8 & 290.1 & 32.2 & 96.6 & 1.10 & 5.63 & 5.00 \\
\hline YU-62 & 828.5 & 668.3 & 1181.2 & 180.6 & 26.0 & 120.5 & 1.28 & 7.48 & 4.10 \\
\hline Ascorbic acid & 63.7 & 59.2 & 59.7 & 48.0 & 6.3 & 11.6 & & & \\
\hline & & & & & & & nd & nd & nd \\
\hline
\end{tabular}

$\overline{\mathrm{a}, \mathrm{b}}$ extract concentration $(\mu \mathrm{g} / \mathrm{mL})$ capable of causing $50 \%$ inhibition of DPPH/ABTS radical, in assay conditions (respectively). ${ }^{\mathrm{c}} \mu \mathrm{g}$ gallic acid $/ 100 \mathrm{~g}$.

DPPH and ABTS radical scavenger assays allows evaluating ability of the extracts in stabilizing free radicals (Huang et al., 2005). In this way, M. alba extracts were also screened by these assays. The first one was conducted to observe DPPH radical scavenger activity and the concentration of each extract $(\mu \mathrm{g} / \mathrm{mL})$ able to inhibit $50 \%$ of DPPH radicals, under the conditions assayed, is shown in Table 2 . The variety more active in this assay among the ethanol extracts was IZ 64, followed by Cubana variety (Table 2). These two cultivars presented extracts far more active than the other in general. It is noteworthy that one of them is a natural variety while the other one (IZ 64) is a hybrid one. Varieties Tigreada and IZ 15/7 presented the highest DPPH scavenging activities among the aqueous extracts, a value comparable to the activities of the corresponding ethanol extracts, showing that, in some case, extracting solvent is secondary in respect to the cultivar type on a bioassay response. It is worth mentioning that hexane extracts from varieties IZ 40, IZ 15/7 and Murcia were as active as some ethanol and aqueous extracts, reinforcing the previous observation on the predominance of the variety properties over solvent extraction, in some cases.

Radical ABTS scavenging activity of ethanol extracts was also assayed and the results are shown in Table 2, indicating that radical inhibition was dose dependent (Figure 2). In this assay, $\mathrm{IC}_{50}$ values found are inversely related to the antioxidant capacity, therefore, variety IZ 64 presented the best activity in this assay among all varieties, when either water or ethanol were used in the extraction process, being more active when ethanol was used. Again, hexane extracts were only weakly active.

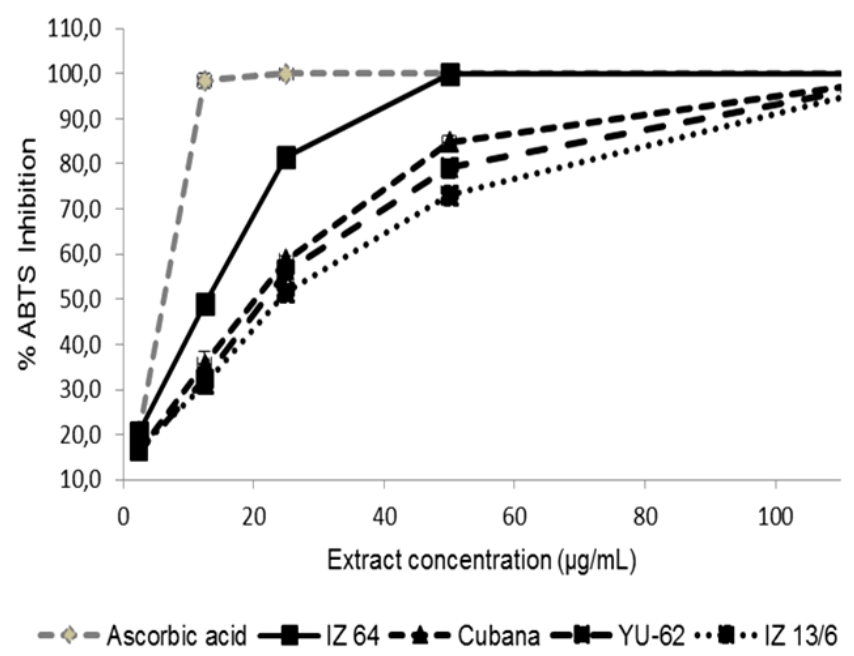

Fig. 2: ABTS radical inhibition by M. alba roots ethanol extracts

Total phenolic compounds present in the extracts were evaluated revealing that such compounds were present in higher 
concentration in ethanol, followed by aqueous and then, by the hexane extracts (Table 1). The lack of phenolic compounds in the hexane extracts is related to the high polarity of such compounds and explain why activity predominates in the extracts prepared from more polar extracting solvents, ethanol and water. Ethanol extracts of IZ 64 variety showed the highest concentration of phenolic compounds (9.85 g gallic acid /100 g extract). Among aqueous extracts, variety IZ $13 / 6$ presented the highest concentration of phenolic compounds, followed by varieties Universidad and YU-12 (6.61; 5.88 and $5.0 \mathrm{~g}$ gallic acid /100 g extract, respectively).

Variety IZ 64 presented outstanding highest flavonoids concentrations being far more active than all other extracts, regardless the extracting solvent used for extracts preparation (Figure 3). This high flavonoid content explains the high antioxidant presented by the extracts of this variety and is also an indicative on the improvements occurred as results of obtaining new hybrid cultivars. Three natural cultivars also presented high flavonoids contents (cubana, tigreada and YU-62), as well as another hybrid cultivar (IZ 40). In some cases, aqueous extracts presented comparable flavonoid contents in relation to the corresponding ethanol extracts; varieties IZ 13/6, IZ 64, IZ 15/7 and Indonesia were the ones more rich in flavonoids, ranging from 234.68 to $204.36 \mu \mathrm{g}$ quecertin /g extract, without significant difference $(\mathrm{p}<0.05)$.

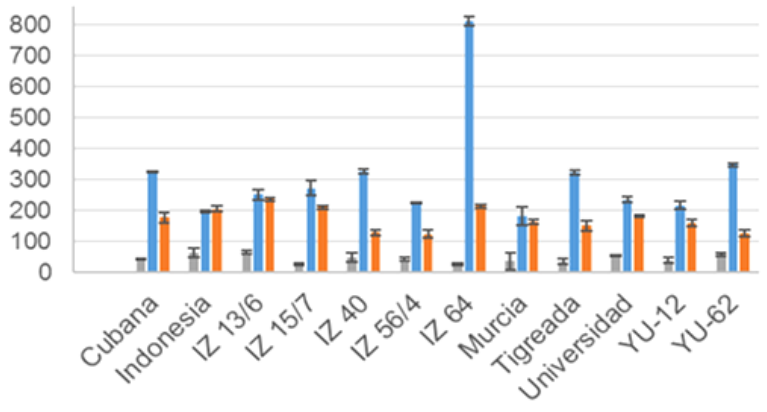

Morus alba varieties (extract of roots)

" hexane "ethanol aqueous

Fig. 3: Total flavonoids content in $M$. alba roots ethanol extracts.

Total phenolic concentration of aqueous extracts studied in this work showed a positive correlation with total antioxidant activity $(r=0.78)$. Besides, total phenolic concentration of ethanol extracts presented strong positive correlation with ferric reducing power $(\mathrm{r}=0.82)$. A strong negative correlation between total phenolic of ethanol and hexane extracts with the $\mathrm{IC}_{50}$ ABTS inhibition $(r=-0.91 ;-0.72)$ and DPPH $(r=-0.77 ;-0.61)$ radicals was also observed.

In total antioxidant activity, ethanol root extracts showed to be 1.4 fold more active than aqueous ones. The later, in turn, showed activity 4.6 fold higher than hexane extracts. These values found to ethanol (708.7 mmol ascorbic acid/g extract) and aqueous extracts (493.4 mmol ascorbic acid/g extract) are much higher than values related for grape (Vitis vinifera) seeds, studied as methanol extracts $(233.0 \mu \mathrm{mol}$ ascorbic acid/g extract) (Jayaprakasha et al., 2003).

The extracts most efficient for DPPH radical scavenging among the varieties tested was IZ $64(378 \mu \mathrm{g} / \mathrm{mL})$. Other Morus extracts have also been reported to be active in this assay (Arabshahi-Delouee and Urooj, 2007). In the present study, activity was detected for extracts from $M$. alba roots, showing that antioxidant compounds are thoroughly distributed in the plant, not relying only in the fruits. Polyphenols have been reported as potential antioxidants, protecting lipids and proteins against oxidative damage through their ability to scavenger metal ions and oxygen and nitrogen free radicals (Andallu et al., 2014). The correlations found between phenolic compounds of ethanol extracts suggest that they act by different mechanisms of action.

All results corroborate that factors such as plant genetic variety affect the composition and concentration of phenolic compounds and, consequently, its antioxidant activity (ParedesLópez et al., 2010). At this context, among all extracts evaluated, ethanol extract of variety IZ 64 presented best antioxidant activity by iron reducing power (Table 1), free ABTS and DPPH radical scavenger (Table 2). Considering the high ABTS free-radical scavenging observed for all assayed extracts (ethanol, aqueous and hexane) of $M$. alba roots from variety IZ 64, it is possible to conclude that this variety has phytochemicals with different polarities possessing antioxidant capacity.

In addition, activities presented by IZ 64 were consistent with its high concentration of phenolic components (Table 2) and flavonoids (Figure 3), which were notably higher than the other ethanol extracts of $M$. alba varieties. Besides, the aqueous extract of the same variety IZ 64 presented the smallest $\mathrm{IC}_{50}$ in ABTS assay $\left(\mathrm{IC}_{50}=53.81\right)$, the second higher concentration of flavonoids among the aqueous extracts (212.37 $\mu \mathrm{g}$ quecertin/g extract), high values for $\mathrm{DPPH}$ inhibition $\left(\mathrm{IC}_{50}=717.11\right)$, total antioxidant activity (532 mmol ascorbic acid/g extract) and ferric reducing power (32.6\% compared to ascorbic acid activity). Knowledge of antioxidant activity of the plants is crucial in exploiting their potential. In this way, these results suggest that among the varieties of $M$. alba evaluated, IZ 64 is the most promising as source of natural antioxidant benefits, as nutraceuticals or in food composition as preservatives.

\section{CONCLUSION}

This work showed the great potential of roots from $M$. alba as antioxidants, as well as detected differences between natural and hybrid varieties of this species related to their antioxidant activities. These differences were, at great extension, also dependent on the solvent used for extracting natural components present in the roots of the cultivars studied. In this way, hexane extracts, which contains mainly non polar compounds such as fatty acids and long-chain alkanes, were consistently the less active ones. Ethanol extracts were always the most active ones, independent on the variety assayed, probably due to the high levels of phenolic and flavonoids compounds that can be extracted 
with ethanol. Antioxidant activity was corroborated by different assays, showing that the compounds present in the extracts act by different mechanisms (radical scavenger and iron reducing power), ethanol being the best solvent to extract compounds with antioxidant activity. Phytochemicals extracted from Morus alba roots with water also showed good antioxidant activities. These results suggest that the making of teas, soft drinks and juices from the roots of this plant could provide antioxidant benefits. Nevertheless, the activity of aqueous extracts was consistently smaller than activity of corresponding ethanol extracts, the former ones can be readily prepared and used by the population, being a good alternative for supply antioxidants to human diet. M. alba variety IZ 64 presented total phenolic and flavonoids concentration bigger than the other varieties screened. This was correlated to its great activity of capturing radicals DPPH, as well as its ability to reduce transition metals. Its ability to capture radical ABTS was also high, independent of the solvent used in the extraction. This shows that in addition to phenolic compounds, there are other components with different polarity and antioxidant activity in roots of $M$. alba.

This work broadens the scope of use of $M$. alba as human food with antioxidant activity (Khan et al., 2013) showing the huge potential of roots from this species for applications in nutraceuticals and food preservatives industry.

\section{ACKNOWLEDGMENTS}

Financial support and sponsorship: The authors acknowledge grants and scholarships from the Brazilian Funding Agencies CAPES (CAPES/MES - CUBA 158/12), CNPq and FAPEMIG.

Conflict of Interests: There are no conflicts of interest.

\section{REFERENCES}

Ahmad A, Gupta G, Afzal M, Kazni I, Anwar F Antiulcer and antioxidant activities of a new steroid from Morus alba. Life Sci, 2013; 92(3):202-210. doi:10.1016/j.lfs.2012.11.020

Akkol EK, Süntar I, Keleş H, Sezik E, Gürler G.. BioassayGuided isolation and characterization of wound healer compounds from Morus nigra L. (Moraceae). Rec Nat Prod, 2015; 9(4):484-495.

Andallu B, Shankaran M, Ullagaddi R, Iyer S. In vitro free radical scavenging and in vivo antioxidant potential of mulberry (Morus indica L.) leaves. J Herb Med, 2014; 4(1):10-17. doi: 10.1016/j.hermed.2013.10.002

Arabshahi-Delouee S, Urooj A. Antioxidant properties of various solvent extracts of mulberry (Morus indica L.) leaves. Food Chem, 2007; 102(4):1233-1240. doi:10.1016/j.foodchem.2006.07.013

Brand-Williams W, Cuvelier ME, Berset C. Use of a free radical method to evaluate antioxidant activity. LWT Food Sci Technol, $1995 ; 28: 25-30$.

Butt MS, Nazir A, Sultan MT, Schroën K. Morus alba L. nature's functional tonic. Trends Food Sci Technol, 2008; 19:505-512. doi: 10.1016/j.tifs.2008.06.002.

Chan EWC, Lye PY, Wong SK. Phytochemistry, pharmacology, and clinical trials of Morus alba. Chin J Nat Med, 2016; 14(1):17-30. doi: 10.3724/SP.J.1009.2016.00017

Chang LW, Juang LJ, Wang BS, Wang MY, Tai HM, Hung WJ, Chen YJ, Huang MH. Antioxidant and antityrosinase activity of mulberry (Morus alba L.) twigs and root bark. Food Chem Toxicol, 2011; 49(4):785-790. doi:10.1016/j.fct.2010.11.045
Donno D, Cerutti AK, Prgomet I, Mellano MG, Beccaro GL. Foodomics for mulberry fruit (Morus spp.): Analytical fingerprint as antioxidants' and health properties' determination tool. Food Res Int, 2015; 69:179-188. doi: 10.1016/j.foodres.2014.12.020.

Egea I, Sánchez-Bel P, Romojaro F, Pretel MT. Six edible wild fruits as potential antioxidant additives or nutritional supplements. Plant Foods Hum Nutr, 2010; 65(2):121-129. doi: 10.1007/s11130-010-0159-3

El-Beshbishy HA, Singab AN, Sinkkonen J, Pihlaja K. Hypolipidemic and antioxidant effects of Morus alba L. (Egyptian mulberry) root bark fractions supplementation in cholesterol-fed rats. Life Sci, 2006; 78(23):2724-2733. doi: 10.1016/j.lfs.2005.10.010

Eo HJ, Park JH, Park GH, Lee MH, Lee JR, Koo JS, Jeong JB. Anti-inflammatory and anti-cancer activity of mulberry (Morus alba L.) root bark. BMC Complement Altern Med, 2014; 14:200. doi: 10.1186/1472-6882-14-200

Gao X, Ohlander M, Jeppsson N, Björk L, Trajkovski V. Changes in antioxidant effects and their relationship to phytonutrients in fruits of sea buckthorn (Hippophae rhamnoides L.) during maturation. J Agric Food Chem, 2000; 48(5):1485-1490. doi: 10.1021/jf991072g

Huang D, Ou B, Prior RL. The chemistry behind antioxidant capacity assays. J Agric Food Chem, 2005; 53:1841-1856.

Jayaprakasha GK, Selvi T, Sakariah KK. Antibacterial and antioxidant activities of grape (Vitis vinifera) seed extracts. Food Res Int, 2003; 36:117-122.

Johnstone C, Day JG, Staines HJ, Benson EE. 2,2'-azinobis-(3ethyl-benzothiazoline-6-sulfonic acid) radical cation decolourisation assay for evaluating total antioxidant status in an alga used to monitor environmental impacts in urban aquatics habitats. Ecol Ind, 2006; 6:280289. doi:10.1016/j.ecolind.2005.03.003

Khan MA, Rahman AA, Islam S, Khandokhar P, Parvin S, Islam MD, Hossain M, Rashid M, Sadik G, Nasrin S, Mollah MNH, AHM Khurshid Alam. A comparative study on the antioxidant activity of methanolic extracts from different parts of Morus alba L. (Moraceae). BMC Res Notes, 2013; 6: 24. doi: 10.1186/1756-0500-6-24

Kim GN, Kwon YI, Jang HD. Mulberry leaf extract reduces postprandial hyperglycemia with few side effects by inhibiting $\alpha$ glucosidase in normal rats. J Med Food, 2011; 14(7-8):712-717. doi:10.1089/jmf.2010.1368

Kim SB, Chang BY, Jo YH, Lee SH, Han SB, Hwang BY, Kim SY, Lee MK. Macrophage activating activity of pyrrole alkaloids from Morus alba fruits. J Ethnopharmacol, 2013; 145(1):393-396. doi: 10.1016/j.jep.2012.11.007

Kurniati NF, Suryani GP, Sigit JI. Vasodilator effect of ethanolic extract of mulberry leaves (Morus alba L.) in rat and rabbit Procedia Chemistry, 2014; 13:142-146. doi: 10.1016/j.proche.2014.12.018

Martín G, Noda Y, Arias Y, Pentón G, Prieto M, Brunet J, Castañeda L. Evaluation of the vegetative reproduction capacity of mulberry (Morus alba L.) varieties. Pastos y Forrajes, 2014; 37(2):217-21

Medina MG, García DE, Moratinos P, Cova LJ. La morera (Morus spp.) como recurso forrajero: avances y consideraciones de investigación. Zootecnia trop, 2009; 27(4):343-362.

Nam S, Jang HW, Shibamoto T. Antioxidant activities of extracts from teas prepared from medicinal plants, Morus alba L., Camellia sinensis L., and Cudrania tricuspidata, and their volatile components. J Agric Food Chem, 2012; 60(36):9097-9105. doi: $10.1021 / \mathrm{jf3} 301800 \mathrm{x}$

Noda Y, Pentón G, Martín G. Comportamiento de nueve variedades de Morus alba (L.) durante la fase de vivero. Pastos y Forrajes, 2004; 27(2):131-138

Olajuyigbe OO, Afolayan AJ. Phenolic content and antioxidant property of the bark extracts of Ziziphus mucronata Willd. subsp. mucronata Willd. BMC Complement Altern Med, 2011; 11:130. doi:10.1186/1472-6882-11-130

Oliveira AM, Nascimento MF, Ferreira MRA, Moura DF, Souza TGS, Silva GC, Ramos EHS, Paiva PMG, Medeiros PL, Silva TG, Soares LAL, Chagas CA, Souza IA, Napoleão TH. Evaluation of acute toxicity, genotoxicity and inhibitory effect on acute inflammation of an ethanol extract of Morus alba L. (Moraceae) in mice. J Ethnopharmacol, http://dx.doi.org/10.1016/j.jep.2016.09.004 
Oyaizu M. Studies on product of browning reaction prepared from glucose amine. Jpn J Nutr, 1986; 44:307-315.

Paredes-López O, Cervantes-Ceja ML, Vigna-Pérez M, Hernández-Pérez T. Berries: improving human health and healthy aging, and promoting quality life - a review. Plant Foods Hum Nutr, 2010; 65(3):299-308. doi: 10.1007/s11130-010-0177-1

Prieto P, Pineda M, Aguilar M. Spectrophotometric quantitation of antioxidant capacity through the formation of a phosphomolybdenum complex: specific application to the determination of vitamin E1. Anal Biochem, 1999; 269(2):337-341.

Re R, Pellegrini N, Proteggente A, Pannala A, Yang M, RiceEvans C. Antioxidant activity applying an improved ABTS radical cation decolorization assay. Free Radic Biol Med, 1999; 26(9-10):1231-1237. doi:10.1016/S0891-5849(98)00315-3

Rivière C, Krisa S, Péchamat L, Nassra M, Delaunay JC, Marchal A, Badoc A, Waffo-Téguo P, Mérillion JM. Polyphenols from the stems of Morus alba and their inhibitory activity against nitric oxide production by lipopolysaccharide activated microglia. Fitoterapia, 2014; 97:253-260. doi: 10.1016/j.fitote.2014.06.001

Singh G, Kapoor IPS, Singh P, de Heluani CS, de Lampasona MP, Catalan CA. Chemistry, antioxidant and antimicrobial investigations on essential oil and oleoresins of Zingiber officinale. Food and Chem Toxicol, 2008; 46: 3295-3302.

Umamaheswari M, Chatterjee TK. In vitro antioxidant activities of the fractions of Coccinia grandis L. leaf extract. Afr $\mathrm{J}$ Tradit Complement Altern Med, 2008; 5(1):61-73.

Villaño D, Fernández-Pachón MS, Moyá ML, Troncoso AM, García-Parrilla MC. Radical scavenging ability of polyphenolic compounds towards DPPH free radical. Talanta, 2007; 71(1):230-235. doi: 10.1016/j.talanta.2006.03.050
Wei H, Zhu JJ, Liu XQ, Feng WH, Wang ZM, Yan LH. Review of bioactive compounds from root barks of Morus plants (Sang-Bai-Pi) and their pharmacological effects. Cogent Chem, 2016; 2: 1212320. doi:10.1080/23312009.2016.1212320

Yang J, Paulino R, Janke-Stedronsky S, Abawi F. Free-radicalscavenger activity and total phenols on noni (Morinda citrifolia L.) juice and powder in processing and storage. Food Chem, 2007; 102(1):302-308 doi:10.1016/j.foodchem.2006.05.020

Yangthong M, Hutadilok-Towatana N, Phromkunthong W. Antioxidant activities of four edible seaweeds from the southern coast of Thailand. Plant Foods Hum Nutr, 2009; 64(3):218-223. doi: 10.1007/s11130-009-0127-y

\section{How to cite this article:}

Sande D, Solares MD, Rodríguez YEM, Cabrera IC, Carballo LF, Pérez NA, Morales YL, Colen G, Takahashi JA. Roots from mulberries (Morus alba) natural and hybrids varieties: phenolic contend and nutraceutical potential as antioxidant. J App Pharm Sci, 2016; 6 (11): 063-069. 